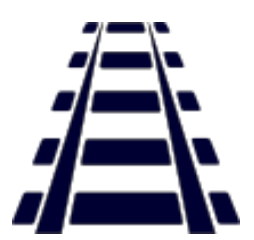

Demiryolu Mühendisliği

Ocak 2022

Say1:15, Sayfa: $125-133$

Araştırma Makalesi

doi: 10.47072/demiryolu.1030404

http://dergipark.org.tr/demiryolu

e-ISSN: 2687-2463, ISSN: 2149-1607
Railway Engineering

Jan. 2022

Issue:15, Page: 125-133

Research Article

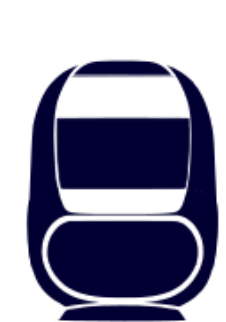

\title{
Tünel Projelendirilmesinde Kullanılan Yöntemler (Ampirik, Analitik ve Nümerik Yöntemler), Kısıtlamaları, Karşılaştırılması ve Öneriler
}

\author{
Ebu Bekir AYGAR
}

Fugro Sial Yerbilimleri Müşavirlik ve Mühendislik Ltd. Şti. Ankara, Türkiye

eaygar@gmail.com

(Alınıs/Received: 30.11.2021, Kabul/Accepted: 06.01.2022, Yayımlama/Published: 31.01.2022)

\begin{abstract}
Öz: Son dönemlerde altyapı çalışmalarına ağırlık verilmiş olan ülkemizde tünelcilik faaliyetleri çok hızlı bir şekilde artış göstermiştir. Özellikle Yüksek Hızlı Demiryolu Projelerinde güzergahın kısıtlamalarından dolayı tünel sayısının arttığı daha net görülmüştür. Ülkemizdeki büyük alt yapı projelerinden olan Ankara İstanbul, Bursa Yenişehir, Ankara Konya, Kars Tiflis, Ankara Sivas ve Ankara İzmir arası Yüksek Hızlı Tren Projelerinde kazı çalışmaları devam etmektedir. Bu kesimlerde yer alan tünellerden bir kısmı tamamlanmış olup diğerlerinde kazı çalışmaları devam etmektedir. Söz konusu büyük projelerden edinilen tecrübeler ile bu çalışmada kapsamında tünel projelendirilmesi sırasında takip edilen yöntemler anlatılarak yöntemlerdeki kısitlamalar, avantajlar ve dezavantajlar değerlendirilecektir.
\end{abstract}

Anahtar kelimeler: Tünel projelendirilmesi, Kaya sınıflandırma sistemleri, Analitik yöntemler, Nümerik yöntemler.

\section{Methods Used in Tunnel Design (Empirical, Analytical and Numerical Methods), Limitations, Comparison and Suggestions}

\begin{abstract}
Tunneling activities have increased rapidly in our country, which has recently focused on infrastructure works. Especially in High Speed Railway Projects, this situation has been seen more clearly due to the restrictions of the route. Excavations continue in High Speed Railway Projects between Ankara Istanbul, Bursa Yenişehir, Ankara Konya, Kars Tbilisi, Ankara Sivas and Ankara Izmir, which are among the major infrastructure projects in our country. Some of the tunnels in these sections have been completed and excavations are continuing in the others. The experiences gained from these big projects and the methods followed during the tunnel design will be explained within the scope of this study, and the limitations, advantages and disadvantages of the methods will be evaluated.
\end{abstract}

Keywords: Tunnel project, Rock Mass Classification system, Analytical methods, Numerical methods.

\section{Giriş}

Tünelcilik yüzyıllar öncesinden gelişmeye başlamış ve günümüze kadar devam etmiştir. İlk dönemlerde barınma ve korunma amacıyla açılan tüneller sağlam kayalarda açılmıştır. Sonraki dönemlerde ise ulaşım, sulama gibi faaliyetleri için açılmaya başlamıştır. 1900'lü yıllarda artan sanayileşmeye bağlı olarak tünelcilik faaliyetleri hızlanmıştır. Tünel kaya sınıflama sistemleri ise bu çalışmalara bağlı olarak gelişmiştir. Terzaghi [1], Deere [2], Bieniawski [3], [4], [5], Barton vd [6], [7], [8], Rabcewicz [9], [10], [11] Palmstrom [12] Hoek ve Brown [13], [14] tünel kaya sınıflamaları için çok önemli çalışmalar yapmışlardır. Yapılan bu çalışmalar günümüz tünel projelendirme aşamalarında kullanılmaktadır.

Bu çalışmalarda Terzaghi [1] tünel üzerindeki kaya yüküne bağlı olarak çelik iksaları boyutlandırmıştır. Bu çalışma tünelcilik açısından en önemli çalışmalardan birisidir [15]. Deere [2] ise sondajlarda, kaya kütlesinin süreksizlik özelliklerine bağlı olarak ortaya çıkan karot verimini esas alan kaya kalite göstergesini (RQD) tanımlamıştır. Bieniawski [3], [4], [5], kaya kütle puanı (RMR) sistemini geliştirmiş ve günümüzde hala en çok kullanılan kaya kütlesinin 
jeomekanik özelliklerine dayalı puanlama sistemi geliştirerek, günümüzde tünel çalışmalarında en çok kullanılan sınıflama sistemi olan, kaya kütlesi sınıflama sistemini (RMR) geliştirmiştir. Bieniawski [3] ilk çalışmasını 1973 yılında yayınlamış ve 1989 yılında [5] RMR sisteminin son haline getirmiştir. Barton vd [6], [7], [8] 1973 yılından 1989 yılına kadar yaptığı çalışmalar ile Q sistemini geliştirmişlerdir. Rabcewiz [9], [10], [11] 1964'lü y1llardan itibaren Yeni Avusturya Tünelcilik Yöntemi'nin (NATM) temellerini atmış, sonrasında Rabcewicz ve Golser [15], Müller [16] de NATM'in prensiplerini belirlemişlerdir. İlerleyen dönemlerde ise Palmstrom [12] kaya kütle indexi (RMi) üzerine çalışmış olup Hoek ve Brown [14] jeolojik dayanım indeksi (GSI) değerini belirleyerek kaya kütle sınıflama sistemlerine önemli katkılarda bulunmuşlardır.

Kaya kütle sistemlerine bağlı olarak analitik çözümlerde 1900'lü yıllardan itibaren gelişmeye başlamıştır. $\mathrm{Bu}$ yöntemlerde ortamın izotrop, homojen ve tünelin dairesel olduğu prensipler üzerinden gidilerek tünel çevresinde ve zeminde deformasyon gerilme ilişkileri elde edilmiştir [17], [18], [19], [20], [21].

Bilgisayar teknolojisinin ilerlemesine bağlı olarak 1980'li yıllardan itibaren de sayısal (nümerik) çözümler geliştirilmiş̧ir. Bu yöntemlerde sonlu elemanlar, sonlu farklar, ayrık elemanlar ve hibrit elemanlar [22], [23], [24], [25], [26], [27], [28] kullanılarak tünel ile kaya ortamı modellenerek çok daha kesin çözümlere ulaşılmıştır. Günümüz tünel projelendirme aşamalarında bu üç yöntem beraber kullanılmaktadır.

$\mathrm{Bu}$ çalışma kapsamında tünel projelendirme çalışmalarında kullanılan bu yöntemler hakkında bilgiler verilecek ve her bir yöntemin avantaj ve dezavantajları üzerinde durulacaktır. Ayrıca ampirik yöntemlerdeki kısıtlamalar hakkında bilgiler verilecektir.

\section{Ampirik Yöntemler}

Bu bölümde kaya sınıflama sistemi olarak kullanılan ampirik metotların kısıtlamaları üzerinde durulacaktır. Ayrıca her bir metodun destek önerileri ve temel aldığı parametreler açıklanacaktır.

\subsection{Terzaghi kaya sınıflama sistemi}

Terzaghi [1] yapmış olduğu çalışmada tünel kaya sınıflama sistemi olarak 9 ana bölüme ayırmıştır. Burada sağlam kayadan şişen kayaya kadar bölümlendirmiş ve her bir sınıf için destek sistemi önerilerini vermiştir. Burada tünel yükseklik ve çapına bağlı olarak tünel üzerine gelen yükü belirlemiş ve çelik tahkimat tipleri hakkında öneri sunmuştur. Terzaghi [1] kaya sınıflama sistemi, klasik olarak açılan delme ve patlatma yöntemi ile açılan tünellerde çelik iksalar üzerine önerileri vardır. Çelik iksa haricinde günümüzde kullanılan bulon, püskürtme beton, hasır çelik, çelik tel için bir önerisi o dönem içerisinde önerisi yoktur.

\subsection{Kaya kalite indeksi (RQD)}

Deere [2] sondaj karotları kalitesine göre bir sınıflandırma geliştirmiştir. Burada RQD belirlenirken sondaj karotlarından elde edilen $10 \mathrm{~cm}$ 'den büyük örneklerin toplamının toplam karot uzunluğuna bölünmesi ile yüzde olarak hesaplanır. Denklem 1. de RQD değerinin hesaplanması verilmiştir. Tablo 1. de RQD ve kaya kalitesi ilişkisi verilmiştir.

$$
R Q D=\frac{10 \mathrm{~cm} \text { den büyü } k \text { örneklerin uzunluklarının toplamı }}{\text { toplam sondaj uzunluğ } u} * 100
$$

Belirlenen RQD değerine göre kaya kalitesi 5 ana bölüme bölünmüştür. 
Tablo 1. RQD ve kaya kalitesi ilişkisi [2]

\begin{tabular}{ccc}
\hline & RQD $(\%)$ & Kaya Kalitesi \\
\hline 1 & $<25$ & Çok zayif \\
2 & $25-50$ & Zayif \\
3 & $50-75$ & Orta \\
4 & $75-90$ & Iyyi \\
5 & $90-100$ & Mükemmel \\
\hline
\end{tabular}

Deere [2] burada sadece kaya kalitesini belirlemek amacıyla sınıflandırma sistemi geliştirmiştir.

\subsection{RMR kaya sinıflama sistemi}

Bineniawski [3], [4], [5], 1973 yılından 1989 y1lına kadar geçen sürede RMR sisteminin son haline ulaşmıştır. Burada RMR sistemi 6 ana girdi parametresi vardır. Tablo 2'de sunulan bu girdi parametreleri ayrı ayrı puanlanarak RMR değerine ulaşılmaktadır. RMR değerlerine göre de tünel 5 ana kaya sınıfına ayrılmış (Tablo 3) ve her bir kaya sınıfı içinde 5 destek sistemi önerilmektedir (Tablo 4).

Tablo 2. RMR kaya sinıflama sistemi girdi parametreleri [5]

\begin{tabular}{ll}
\hline No & Girdi parametresi \\
\hline 1 & Tek eksenli basınç direnci (UCS) \\
2 & Kaya kalite göstergesi (RQD) \\
3 & Süreksizlik aralığı \\
4 & Süreksizlik koşulları \\
5 & Yeraltı suyu durumu \\
6 & Süreksizlik yönelimi \\
\hline
\end{tabular}

Tablo 3. RMR kaya sinıflama sistemi [5]

\begin{tabular}{|c|c|c|c|}
\hline $\begin{array}{l}\text { Kaya } \\
\text { numaras1 }\end{array}$ & Sinifi & RMR Puanı & Kaya Sınıfı \\
\hline 1 & & $81-100$ & Çok iyi kaya \\
\hline 2 & & $61-80$ & İyi kaya \\
\hline 3 & & $41-60$ & Orta kaya \\
\hline 4 & & $21-40$ & Zayıf kaya \\
\hline 5 & & $0-20$ & Çok zayif kaya \\
\hline
\end{tabular}

Tablo 4. Tünel destek sistemi önerisi [5]

\begin{tabular}{|c|c|c|c|c|}
\hline Kaya kütle sınıfı & Kaz1 & $\begin{array}{c}\text { Kaya bulonu (20 } \\
\text { mm çapl1, } \\
\text { enjeksiyonlu) }\end{array}$ & Püskürtme beton & Çelik iksa \\
\hline I-Çok iyi kaya & Tam kesit & \multicolumn{3}{|c|}{ Genellikle destek gerekmez sadece yerel bulonlama } \\
\hline RMR:81-100 & $3 \mathrm{~m}$ ilerleme & & & \\
\hline & Tam kesit & Tavan kesiminde & Tavanda & \multirow[t]{2}{*}{ Yok } \\
\hline $\begin{array}{c}\text { II-İyi kaya } \\
\text { RMR:61-80 }\end{array}$ & $\begin{array}{c}\text { 1-1,5 m ilerleme. } \\
\text { Tünel aynası } \\
\text { gerisinde tünel } \\
\text { destekleri } \\
\text { tamamlanmış } \\
\text { olacak. }\end{array}$ & $\begin{array}{c}\text { 2,5 m aralıklı } 3 \mathrm{~m} \\
\text { uzunlukta } \\
\text { bulonlar+hasır } \\
\text { çelik }\end{array}$ & $\begin{array}{c}\text { gerekmesi } \\
\text { durumunda } 50 \\
\text { mm kalınlıkta } \\
\text { püskürtme beton }\end{array}$ & \\
\hline III-Orta kaya & Üst yarı ve alt yarı. & $1,5-2,0 \mathrm{~m}$ aralıklı & Tavan kesiminde & \multirow[t]{2}{*}{ Yok } \\
\hline RMR:41-60 & $\begin{array}{c}\text { 1,5-3,0 m ilerleme. } \\
\text { Tüm destekler } \\
\text { aynanın } 10 \mathrm{~m} \\
\text { gerisinde } \\
\text { tamamlanmıs } \\
\text { olacak. }\end{array}$ & $\begin{array}{l}4 \text { m uzunluğunda } \\
\text { sistematik } \\
\text { bulonlar, tavanda } \\
\text { hasır çelik }\end{array}$ & $\begin{array}{c}50-100 \mathrm{~mm} \text { alt } \\
\text { yarı kesimlerinde } \\
30 \mathrm{~mm} \text { püskürtme } \\
\text { beton }\end{array}$ & \\
\hline
\end{tabular}




\begin{tabular}{|c|c|c|c|c|}
\hline $\begin{array}{c}\text { IV-Zayıf kaya } \\
\text { RMR:21-40 }\end{array}$ & $\begin{array}{l}\text { Üst yarı ve alt yarı. } \\
\text { 1,0-1,5 m ilerleme. } \\
\text { Tüm destekler } \\
\text { aynanın } 10 \mathrm{~m} \\
\text { gerisinde } \\
\text { tamamlanmış } \\
\text { olacak. }\end{array}$ & $\begin{array}{l}\text { 1-1,5 m aralıklı 4- } \\
5 \text { m uzunluğunda } \\
\text { sistematik } \\
\text { bulonlar ve üst } \\
\text { yarı ve alt yarıda } \\
\text { hasır çelik }\end{array}$ & $\begin{array}{c}\text { Tavanda } 100-150 \\
\text { mm alt yarıda } 100 \\
\text { mm püskürtme } \\
\text { beton }\end{array}$ & $\begin{array}{l}\text { Gerektiği yerde } \\
1,5 \mathrm{~m} \text { aralıklı } \\
\text { hafif-orta çelik } \\
\text { iksalar }\end{array}$ \\
\hline $\begin{array}{c}\text { V-Çok zayıf } \\
\text { kaya } \\
\text { RMR<20 }\end{array}$ & $\begin{array}{l}\text { Kademeli kazı. } \\
\text { 0,5-1,5 m ilerleme. } \\
\text { Destekler kazıdan } \\
\text { hemen sonra } \\
\text { tamamlanacak. } \\
\text { Püskürtme beton } \\
\text { patlatmadan hemen } \\
\text { sonra yapilacak }\end{array}$ & $\begin{array}{l}\text { 1-1,5 m aralıklı 5- } \\
6 \text { m uzunluğunda } \\
\text { sistematik } \\
\text { bulonlar ve hasır } \\
\text { çelik. İnvert } \\
\text { kesiminde bulon } \\
\text { uygulanacak }\end{array}$ & $\begin{array}{l}\text { Tavanda } 150-200 \\
\text { mm püskürtme } \\
\text { beton, } 150 \mathrm{~mm} \text { alt } \\
\text { yarıda ve } 50 \mathrm{~mm} \\
\text { aynada }\end{array}$ & $\begin{array}{c}\text { Orta-ağır çelik } \\
\text { iksalar, 0,75 m } \\
\text { aralıklı, } \\
\text { gerekmesi } \\
\text { durumunda süren. } \\
\text { Invert ile tünel } \\
\text { kapatılacak. }\end{array}$ \\
\hline
\end{tabular}

Bieniawski [5] RMR kaya sınıflama sisteminde RMR'de destek sistemi önerisi, başlıca; at nalı tünel kesiti ile en büyük $10 \mathrm{~m}$ tünel açıklığ 1 ve $25 \mathrm{MPa}$ düşey gerilme koşullarıyla sınırlıdır. Ayrıca, önerilen destek sistemleri incelendiğinde, püskürtme beton kalınlı̆̆ı, bulon uzunluğu, çelik iksa tip önerilerinde bir aralık tanımlandığı ve kesin bir boyutlandırma vermediği görülmektedir. Ayrıca önerilen destek sistemleri incelendiğinde kesin bir boyutlandırma vermediği görülmektedir. Püskürtme beton kalınlığı, bulon uzunlukları, çelik iksaların tipi belirtilirken bir aralık vermektedir. Kesin bir boyut mevcut değildir. Bununla beraber kaya sınıfları belirlenirken RMR puanı aralığ 20 olarak belirlenmiştir. Diğer bir ifade ile, RMR değeri 61 de iyi kaya 80 de iyi kayadır ve aynı destek sistemi önerilir. Benzer şekilde RMR değeri 60 ise orta kaya 61 ise iyi kaya olarak sınıflandırılır ve farklı destekler önerilir.

\section{4. $Q$ sistemi}

Barton vd [6] 200'e yakın tünel ve yeraltı açıklıklarına yapmış oldukları çalışmalarda Q sistemini geliştirmişlerdir. Q değerinin belirlenmesinde 6 adet girdi parametresi kullanılmakta olup Denklem 2. de verilmiştir.

$$
Q=\left(\frac{R Q D}{J n}\right) *\left(\frac{J r}{J a}\right) *\left(\frac{J w}{S R F}\right)
$$

Burada

$\mathrm{RQD}=$ kaya kalite göstergesi

$\mathrm{Jn}=$ eklem takım sayısı

$\mathrm{Jr}=$ eklem pürüzlülük sayısı

$\mathrm{Ja}=$ eklem alterasyon sayıs1

$\mathrm{JW}=$ eklem su azaltma faktörü

$\mathrm{SRF}=$ gerilim indirgeme faktörüdür.

Belirlenen Q değeri, açılacak olan tünelin çapının veya yüksekliğinin tünel tipine göre belirlen kazı destek oranına bölünmesi ile elde edilen orana göre destek sistemi belirlenir (Tablo 5). Q sisteminde kaya toplam 9 adet sınıfa bölünmüş olup, olağanüstü iyiden olağanüstü zayıfa kadar değişen aralıkta tanımlanır. Bu tanımlamadan sonra da tünel destek sistemleri belirlenmektedir. Destek sistemleri ise Tablo 6. da özetlenmektedir. 
Tablo 5. Q sistemine göre destek tipleri [6]

\begin{tabular}{llc}
\hline & \multicolumn{1}{c}{ Kazı kategorisi } & ESR (Kazı destek oranı) \\
\hline A & $\begin{array}{l}\text { Geçici maden kazıları } \\
\text { B }\end{array}$ & $\begin{array}{l}\text { Kalıcı maden kazıları, hidroelektrik santralleri } \\
\text { için su tünelleri, pilot tüneller, geniş kazılar }\end{array}$ \\
& $\begin{array}{l}\text { için açıklıklar } \\
\text { Depo odaları, su arıtma tünelleri, küçük yol ve } \\
\text { demiryolu tünelleri, erişim tünelleri }\end{array}$ & 1.6 \\
D & $\begin{array}{l}\text { Ana demiryolu ve karayolu tüneller, güç } \\
\text { istasyonları, portal bölgeleri, sivil savunma } \\
\text { odaları }\end{array}$ & 1.3 \\
Yeraltı nükleer santralleri, demiryolu & 1.0 \\
istasyonları, fabrikalar, spor ve kamu tesisleri & 0.8 \\
\hline
\end{tabular}

Tablo 6. Q sistemine göre destek tipleri [6]

\begin{tabular}{cc}
\hline Destek sistemi & Destek detayları \\
\hline 1 & Desteksiz \\
2 & Yerel bulonlama \\
3 & Sistematik bulonlama \\
4 & Sistematik bulonlama, ve püskürtme beton $4-10 \mathrm{~cm}$ \\
5 & Fiber ile güçlendirilmiş püskürtme beton $(5-9 \mathrm{~cm})$ ve bulonlama \\
6 & Fiber ile güçlendirilmiş püskürtme beton $(9-12 \mathrm{~cm})$ ve bulonlama \\
7 & Fiber ile güçlendirilmiş püskürtme beton $(12-15 \mathrm{~cm})$ ve bulonlama \\
8 & Fiber ile güçlendirilmiş püskürtme beton, $>15 \mathrm{~cm}$, çelik iksa ve bulonlama \\
9 & Beton kaplama \\
\hline
\end{tabular}

\subsection{Yeni Avusturya Tünelcilik Yöntemi (NATM)}

Rabcewicz [9], [10], [11], Rabcewicz ve Golser [15], [16] tarafinda geliştirilen NATM metodu son dönemlerde klasik tünelcilik yönteminin yerini almaya veya klasik tünelcilik NATM şeklinde adlandırılmaya başlanmıştır. NATM yöntemi azımsanamayacak kadar uzun zamandır etkin bir yöntem olarak kullanılmaktadır. Aksine; son yıllarda, bilindiği gibi çoğu projede maliyet ve uygulanabilirlik koşullarının değerlendirilmesiyle, NATM yönteminin kullanılması yerine TBM veya EPBM kazıları seçilmektedir. NATM'in genel prensibi deformasyonlara izin vererek tünel çevresinde koruyucu bir zon oluşturma prensibine dayanır. NATM sistemi esnek bir diş kemer ilkesine dayanmakta olup kalın kaplamalardan kaçınılmaktadır. Ana destek sistemi olarak bulon, çelik iksa, püskürtme beton kullanılmaktadır. Bu yöntemde tünel A1 den C5'e kadar değişen 10 alt sınıfa bölünmektedir. Tablo 7. de NATM kaya sınıflama sistemi verilmiştir.

Tablo 7. NATM kaya sinıflandırma sistemi [29]

\begin{tabular}{lll}
\hline Kaya sınıfi & ÖNORM B2203 Ekim 1994 sonras1 \\
\hline A & A1 & Stabil \\
& A2 & Sonradan az sökülen \\
B & B1 & Gevrek \\
& B2 & Çok gevrek \\
& B3 & Daneli \\
C & C1 & Dağ atma \\
& C2 & Bask1lı \\
& C3 & Çok baskılı \\
& C4 & Akıcı \\
& C5 & Şişen \\
\hline
\end{tabular}

NATM de ülkemizde en sık karıştııılan kaya sınıf C1'dir. C1 kaya sınıfı B3 kaya sınıfında sonra gelmesi sebebi ile, B3 kaya koşullarından daha kötü olan zeminlerde $\mathrm{C} 1$ olarak belirtilmektedir. Ancak C1 kaya sınıfı yüksek örtü altında $(\mathrm{H}=500-600 \mathrm{~m})$ sağlam masif kayalarda dağ atma (rock bursting) şeklinde olmaktadır. Burada birimin tektonizma geçirmemiş olması ve birim içerisinde 
gerilmelerin birikerek kazı sonrasında anlık olarak kayanın patlama şeklinde yenilmesi şeklinde gözlenir. Ülkemizin tektonik unsurlar içerisinde aktif fay zonlarında yer alması sebebi ile görülmesi pek olası değildir.

\section{Analitik ve Nümerik Yöntemler}

Analitik çözümler Kirsch [17], Kastner [18], Sulem vd. [19] Hoek ve Brown [15] Hoek [20], [21] gibi araştırmacılar tarafından geliştirilmiştir. Analitik yönteme göre ortam homojen ve izotrop kabul edilir. Yani yapılan tüm çalışmalar idealize edilmiş bir ortam içerisinde yürütülmektedir. Ancak uygulama aşamasında tünelin geçeceği birim izotrop ve homejen değildir. Bu sebeple analitik çözümlerde kısıtlamalara sahiptir.

Nümerik analiz yöntemleri, 1940 lı yıllardan itibaren geliştirilmeye başlanmıştır. 1960 lı yıllarda Clough [26] tarafından nümerik analiz yöntemi elastitise problemlerinde kullanılmaya başlanmıştır. Hrenikoff [27], Newmark [28] ile temelleri ortaya atılmaya başlanmıştır. Mühendislik problemlerine matematiksel eşitlikler ile çözüm arayan bir yöntem olarak karşımıza çıkmaktadır. Son dönemlerde bilgisayar teknolojisinin gelişimine bağlı olarak uygulama aralığ artmış ve sürekli geliştirilmiştir. Nümerik analiz yöntemleri sonlu elemanlar, sonlu farklar, ayrık elemanlar ve hibrid yöntemler olarak ayrılmaktadır. Nümerik analizler ile mevcut ortam birebir tanımlanabilmekte ve tünelde uygulanacak olan destek sistemleri aynen modele girilebilmektedir. Bilgisayar teknolojisinin gelişmesine bağlı olarak çok karışık olan tünel kazı yöntemleri modellenebilmektedir. Maden galerilerindeki çoklu tüneller, ulaşım tünellerindeki birleşim yapıları, metro istasyonları gibi komplike yapılar aynen modellenerek çözümler ve elde edilen sonuçlar çok daha doğru sonuçlar vermektedir. Günümüzde sonlu elemanlar yöntemi ile çalışan Phase2d programı, sonlu farklar ile çalışan Flac2d ve Flac3d, ayrık elemanlar ile çalışan UDEC programları tünel projelerinde ağırlıklı olarak kullanılmaktadır.

$\mathrm{Bu}$ yaklaşımlar arasında nümerik analizler günümüzde tüm tünel projelerinin vazgeçilmez bir parçası olarak kullanılmaktadır [22], [23], [24], [25]. Nümerik analiz yöntemler arasında ise sonlu elemanlar göreceli daha yaygın bir şekilde kullanılmaktadır. Tünel projelerinde öncelikle ampirik yöntemler ile tünel destek sistemleri kabaca tanımlanmalı, analitik yöntemler ile bu durum detaylandırılmalı ve nümerik çözümler ile de nihai desek sistemleri belirlenmelidir.

Tünel kazısı sırasında yapılacak olan tünel ölçüm metotları (enstümantasyon) de uygulama aşamasında projelerin revizyonu için son derece önemlidir. Zira nihai boyutlandırma tünel kazısı boyunca yapılacak enstrümantasyon ölçümleri ile olmaktadır. Bulon boylarının uzunluğunun tahmini, püskürtme beton veya iç kaplama betonu kaplama kalınlı̆̆ı, çelik iksanın boyutlandırılması doğrudan enstrümantasyon ölçümleri ile alakalıdır. Projelendirme aşamasında hesaplamalar ile kabul edilen plastik zon yarıçapına bağlı olarak bulon boyları tünel kazısı sırasında yapılacak olan ekstansometre ölçümleri ile netleştirilmelidir. Kaplama kalınlığ ve çelik iksa ise, kaplama içine yerleştirilecek olan basınç hücreleri ile gerilmeler belirlenmektedir. Gerilmeler proje değerleri ile karşılaştırılarak kontrolü yapılmalıdır. Ayrıca tünel ilerlemesine bağlı olarak yapılacak olan deformasyon ölçümleri iç kaplamanın hangi aşamada yerleştirileceği hakkında bilgi verecektir. Deformasyon ölçümleri vasıtası ile deformasyon hızı takip edilmeli, üst yarı, alt yarı ve invert kazısı sırasında oluşan deformasyon değişimleri incelenmelidir. Tünel davranışı enstrümantasyon ölçümlerine dayanılarak belirlenmektedir. Ölçülen deformasyon değerleri ile proje değerleri karşılaştırılarak bırakılan deformasyon töleransı kontrol edilmelidir. Enstrümantasyon ölçümlerinden elde edilen sonuçlara göre geri analizler yapılarak tünel projelendirmesi sırasında yapılan kabuller netleştirilmelidir. Böylelikle tünel projeleri tünel kazısı boyunca sürekli olarak güncellenerek en uygun destek sistemi belirlenmelidir. 


\section{Sonuçlar}

Tünel projelendirilmesinde kullanılan yöntemler incelendiğinde aşağıdaki sonuçlara ulaşılmaktadır.

Ampirik yöntemler tünel kaya sınıfının tanımlaması açısından son derece önemlidir. Ancak kaya sınıflarına göre önerilen destek sistemlerinin projelerde aynısının alınması düşünülmemelidir. Kaya sinıflama sistemlerinden önerilen destek sistemleri net olmayıp bir aralık içerisinde vermektedir.

Kaya sınıflama sistemleri yeraltında uygulanmış ve başarılı olan destek sistemlerinin özeti şeklindedir. Ancak her bir kaya sınıflama sistemi kendi içerisinde farklı kısıtlamalar vermektedir. Terzaghi [1] sadece çelik iksalar için öneriler yaparken, Bieniawski [5] önerdiği destek sistemlerinin at nalı şeklinde $10 \mathrm{~m}$ çaplı tüneller için olduğunu belirtmektedir. Ancak Yüksek Hızlı Tren projelerinde tünel kesiti at nalı şeklinde değildir. Tünel kazı genişliği $12 \mathrm{~m}$ ye yakındır. $\mathrm{Bu}$ sebeple kaya sinıflama sistemlerinde verilen destek sistemleri sadece bir yol gösterici olarak alınabilir.

Tüm kaya sınıflama sistemlerinde kaya sınıfları her zaman bir aralık içerisinde verilmektedir. Örneğin RMR sisteminde bu aralık 20 birimdir. Yine örneğin zayıf kaya olarak belirlenen 21 ile 40 arasındaki RMR değerinde, her bir değer zayıf kayadır ve aynı destek uygulanır. Bu durum gerçekçi değildir. RMR değeri 21 ise zayıf kaya olarak başka destek sistemleri uygulanması gerekirken yine zayıf kaya olarak belirlenen RMR değeri 40 olması durumunda ise farklı destek sistemi uygulanmalıdır. Ancak RMR sistemi her iki durum içerisinde aynı desteği önermektedir. Kaya sinıflama sistemleri yapılırken pek çok belirsiz nokta vardır. Bu faktörler arazide belirlenirken bile kişiden kişiye göre farklı yorumlanabilir. Bu farklılıkların olması da normaldir.

Tünel gibi homojen olmayan, anizotrop bir zeminde proje yapılırken hiçbir zaman kesin bir sonuca ulaşılmaz. Çünkü kaya ortamı betonarme veya çelikte olduğu gibi homojen değildir. Her bir metrede bile jeoteknik koşulların değişmesi olasıdır. Tünelin statik bir proje gibi düşünülmemesi gerekir. Tünel kazısı sırasında destek sistemlerinin her an değişebilecek olması sebebi ile dinamik bir projedir. Tünel tamamlandığı zaman tünel projesi tamamlanmış olmaktadır.

Tünel kazısı sırasında yapılacak olan jeolojik-jeoteknik ölçümler, tünel ayna jeolojik haritaları, yatay sondajlar ile tünel kaya sınıfları güncellenmektedir. Buna ek olarak tünel kazısı sırasında projeleri geliştirilerek mevcut duruma göre güncellenmelidir.

Tünel projelendirmesinde tip proje olmamalıdır. Her bir tünelin kendine özgü kaya koşulları vardır. Ayrıca tünelin geçeceği güzergâh yüzeyde bulunan yapılar ile coğrafik durum her zaman değişkendir. Bir tünelde başarılı olan bir destek sistemi farklı bir tünelde başarılı olacak diye bir koşul yoktur. Mühendislik olarak destek sistemlerinin analizi her zaman gerekmektedir.

Tünel projelendirmesi yapılırken öncelikte tünel güzergâhı kaya sınıflarına bölünmektedir. Her bir kaya sınıfı da gerekirse çevresel ve örtü yüksekliğine bağlı olarak ta farklı kısımlara ayrılabilir. Örneğin aynı kaya sınıfı içerisinde farklı örtü yükseklikler var ise kaya sınıfı aynı olsa bile farklı destek sistemleri uygulanabilir. Bu durum nümerik analizler ile detaylandırılarak tünel destekleri boyutlandırılmalıdır. Bir anlamda kaya kütle sınıfı ile destek sitemleri sinıfları ayrı olarak değerlendirilmelidir. NATM kaya sınıfı olarak sıkışan bir kaya ortamında C2 kaya sınıfı tanımlanan birimde, farklı isimlerle adlandırılacak olan örneğin C2 özel, C2 Tip1, C2 Tip2 gibi adlandırmalar olabilir. Çünkü kaya sınıflandırma sistemleri her zaman geniş bir aralık içerisinde yer alır ve bu aralıkta aynı destek sistemini kullanmak çoğu zaman mümkün olmamaktadır. 
Tünel projelendirme aşamasında öncelikle tünelin geçeceği kesimin mühendislik jeolojisi haritası yapılır, sonrasında ise detaylı araştırmalar için sondajlar yapılmaktadır. Bu sondajlardan elde edilen örneklere göre laboratuvar veya sondaj sırasında yerinde (in-situ) deneyler yapılmaktadır. Sondajların karot çapının ortalama $51 \mathrm{~mm}$ olduğu düşüldügünde, $12 \mathrm{~m}$ çaplı bir tünelin projelendirilmesinde bu sondajlar dikkate alınmaktadır. Tünel çapından yaklaşık 235 kat küçük olan bir numuneden elde edilen sonuçlar kullanılmaktadır. Sondajların aralığı ise ortalama 250 m'dir. Bu durum ise tünel projelendirmenin aslında ne kadar çok bilinmezlikleri olduğunu göstermektedir.

\section{Kaynakça}

[1] K.V. Terzaghi, Rock defects and loads on tunnel supports. In: Proctor, R.V. and White, T.L., Eds., Rock Tunneling with Steel Supports, Commercial Shearing and Stamping Company, Youngstown, 1946.

[2] D.U. Deere, "Technical description of rock cores for engineering purposes," Rock Mechanics and Engineering Geology, 1, pp. 16-22, 1964.

[3] Z.T. Bieniawski, "Engineering classification of jointed rock masses," Trans S. Afr. Inst. Civ. Engrs 15, 335-344. 1973.

[4] Z.T. Bieniawski, "Rock mass classification in rock engineering," In Exploration for rock engineering, proc. of the symp., (ed. Z.T. Bieniawski) 1, 97-106. Cape Town: Balkema. 1976.

[5] Z.T. Bieniawski, Engineering rock mass classifications. New York: Wiley. 1989.

[6] N.R. Barton, R. Lien, J. Lunde, "Engineering classification of rock masses for the design of tunnel support," Rock Mech. 6(4), 189-239. 1974.

[7] N. R. Barton, F. Løset, R. Lien, J. Lunde, "Application of the Q-system in design decisions," In Subsurface space, (ed. M. Bergman) 2, 553-561. New York: Pergamon.1981.

[8] N.Barton, "Application of Q-system and index tests to estimate shear strength and deformability of rock masses," In Workshop on Norwegian Method of Tunnelling (pp. 66-84). New Delhi, India,1993

[9] L.v Rabcewicz, "The new austrian tunnelling method, Part One," Water Power, pp 453-457, 1964.

[10]L.v. Rabcewicz, "The new austrian tunnelling method, Part Two," Water Power, pp 511-515, 1964.

[11]L.v. Rabcewicz, "The new austrian tunnelling method, Part Three," Water Power, pp 19-24, 1965.

[12] A.Palmstrom, "RMi-A system for characterizing rock mass strength for use in rock engineering," Journal of Rock Mechanics and Tunnelling Technology, 1(2), 69-108. 1996.

[13]E. Hoek, E.T. Brown, Underground excavations in rocks (p. 527). Institution of Mining and Metallurgy. London: Maney Publishing, 1980.

[14]E. Hoek, E.T. Brown, "The Hoek-Brown failure criterion-A 1988 update," In 15th Canadian Rock Mechanics Symposium (pp. 31-38). 1988.

[15]L.v. Rabcewicz, J. Golser, "Principles of dimensioning the supporting system for the "new austrian tunnelling method," Water Power, Marc, 88-93. 1973.

[16]L. Müller, "Removing misconceptions on the new austrian tunnelling method," Tunnels \& Tunnelling International;10(8):29-32. 1978.

[17]H. Kastner, Static des tunnels und stollenbaues. Berlin/Gottingen:Springer 1962.

[18]E.G. Kirsch, "The theory if elasticity and the need of the strength of materials" (trans.). J Assoc German Eng, 1898;42:797-807, 1898.

[19]C. C. Torres, C. Fairhurst, "Application of the convergence-confinement method of tunnel design to rock masses that satisfy the Hoek-Brown failure criterion," Tunn. Undergr. Space Technol. 15 (2), 18213.2000.

[20]E. Hoek, P.K. Kaiser, W.F. Bowden, Support of underground excavations in hard rock. A.A. Balkema, Rotterdam. 1995.

[21] X.F. Wang, B.S. Jiang, Q. Zhang, M.M. Lu, M. Chen, "Analytical solution of circular tunnel in elasticviscoplastic rock mass," Latin American Journal of Solids and Structures, 2019, 16(6), e210, 2019.

[22] A. Sakcali, H.Yavuz, "Estimation of radial deformations around circular tunnels in weak rock masses through numerical modelling," International Journal of Rock Mechanics and Mining Sciences, 123, 104092. https://doi.org/10.1016/j.ijrmms.2019.104092, 2019.

[23]D.R.J. Owen, E. Hinton, Finite Elements in Plasticity. Pineridge Press, Swansea, p 589, 1980.

[24]M.Cai, "Influence of stress path on tunnel excavation response - numerical tool selection and modeling strategy," Tunn Undergr Sp Technol 23(2008):618-628, 2008. 
[25] M.E.F. Duncan, "Numerical modelling of yield zones in weak rocks," In: Hudson JA (ed) Comprehensive rock engineering, vol 2. Pergamon, Oxford, pp 49-75,1993.

[26] R.W. Clough, "The finite element method in plane stress analysis." In: Proceedings of the 2nd ASCE Conference on Electronic Computation, Pittsburgh, 1960.

[27] A Hrenikoff, Solution of problems in elasticity by the framework method. J. Appl. Mech. 1941; 8, 16975.

[28] NM Newmark. Numerical Methods of Analysis in Engineering. In: LE Grinter (ed.). Macmillan, New York, 1949.

[29] Karayolları Genel Müdürlüğü, Karayollarl Teknik Şartnamesi, 2013.

\section{Özgeçmiş}

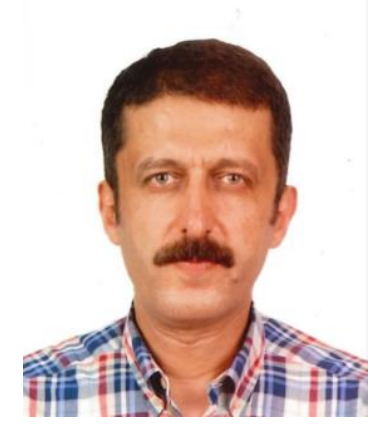

\section{Ebu Bekir AYGAR}

Ebu Bekir Aygar, 1973 Ankara doğumlu olup, Hacettepe Üniversitesi Maden Mühendisliği Bölümünde 1996 Lisans, 2000 Yüksek Lisans ve 2007 de Doktora eğitimini tamamlamıştır. Fugro Sial Müş. ve Müh. Ltd. şirketinde 2009 yılından itibaren Tünel Tasarım Bölüm Müdürü olarak görev yapmaktadır. Uzmanlık alanı olarak Tünelcilik, NATM, Kaya Mekaniği, Nümerik Analizler olarak sıralanabilir. Yazarın ulusal ve uluslararası olmak üzere yayınları mevcuttur. Yazar Türkiye'de ve yurtdışında farklı yüksek hızlı demiryolu ve karayolu tünel projelerinde proje müdürü olarak çalışmıştır.

E-Posta: eaygar@gmail.com

\section{Beyanlar:}

Bu makalede bilimsel araştırma ve yayın etiğine uyulmuştur. 